\title{
O Mimo Corpóreo de Étienne Decrouxe A Busca de Expressividade Segundo A Perspectiva de Artificialidade Grotowskiana
}

\author{
Leela Alaniz \\ Universidade Federal do Rio Grande do Sul - UFRGS \\ Email: leela@pasdedieux.com
}

Se utilizarmos a perspectiva grotowskiana de organicidade e artificialidade para a análise de um evento teatral ou ritual e que, segundo ele, é possível destacar aquilo que é orgânico e aquilo que é artificial, sendo que o primeiro busca as impulsões primeiras para cada ação; e o segundo, procura a forma, a estrutura, onde se situa a Mímica Corporal de Étienne Decroux? Certo, a forma, o rigor e a precisão são fundamentais nesta forma teatral, o que a colocaria dentro da abordagem artificial, mas se a olharmos mais de perto, não seria possível encontrar a organicidade? Este artigo procura trazer à tona, algumas destas questões.

Palavras-chave

Mimo Corpóreo, Linhagem Artificial, Teatro Tradicional Asiático, Jerzy Grotowski, Étienne Decroux
If we use the grotowskian perspective of organicity and artificiality to analyze a theatrical or a ritual event, it is possible to highlight what is organic and what is artificial: i.e., the former searches for the primary impulses for each action; and the latter, looks for the form and the structure. From this prism, where is Etienne Decroux's Corporeal Mime situated? Sure, form, rigor, and precision are fundamental in this theatrical form, which would place it firmly within the artificial end of the spectrum. However, if we look more closely, could we not find the organicity? This article elaborates upon these questions.

Keywords

Corporeal mime, artificial language, Traditional Asiatic Theater, Jerzy Grotowski, Étienne Decroux 
De acordo com Jerzy Grotowski: "Nós podemos realmente analisar cada fenômeno ritual ou teatral, observando em cada um a predominância daquilo que é orgânico e daquilo que é artificial" (Grotowski, 1997). Grotowski define sua própria pesquisa do trabalho do ator como uma pesquisa orgânica. Paralelamente ele define o teatro oriental, sobretudo a Ópera de Pequim, o Teatro Nô japonês e o Kathakali do sul da Índia como abordagens artificiais, considerando que cada uma dessas formas nasce de um modelo estruturado, e não da busca dos impulsos internos do ator.

Os conceitos de organicidade e de artificialidade, de acordo com Grotowski são, a priori, corporais:

Em primeiro lugar, a abordagem orgânica é caracterizada por um processo de liberação para desbloquear e eliminar a resistência física e psicológica para que nele a impulsão e a ação ocorram simultaneamente. Segundo Grotowski, isto significa que é necessário suprimir o tempo que pode existir entre "impulso interior e reação exterior, de modo que o impulso se torna já uma reação exterior. Impulso e ação são concomitantes" (Grotowski, 1992, p. 14).

Em segundo lugar, a abordagem artificial é aquela em que o ator começa com a imitação de uma forma ensinada por um mestre. $\mathrm{O}$ ator se apropria de uma estrutura externa e bastante distinta da gestualidade cotidiana e que não segue um processo interno iniciado pelas impulsões. Grotowski define então as abordagens artificiais no teatro como sendo aquelas "que começam pela composição, por pequenos sinais, pela periferia do corpo, em vez das impulsões" (Grotowski, 1997).

Aparentemente, estas duas abordagens são similares, primeiro no que se refere ao distanciamento do realismo e, segundo, pelo fato das duas adotarem a via do corpo. No entanto, elas se desenvolvem de maneiras distintas, e pode-se mesmo dizer opostas. Mas ambas irão afirmar em suas jornadas, a mesma necessidade de produzir o seu antônimo, o seu contrário. Em outras palavras, a abordagem orgânica exigirá a estrutura (a via artificial), de modo que o carácter orgânico possa finalmente aflorar e ser visto pelo espectador e, por sua vez, a abordagem artificial irá exigir a organicidade, para que sua estrutura esteja sempre viva.

Se Grotowski procurou construir um método baseado em um trabalho orgânico do ator, por sua vez Étienne Decroux ${ }^{1}$, na criação do Mimo Corpóreo, realmente deu ao ator uma linguagem que, utilizando todas as possibilidades da ferramenta, que é o seu corpo, lhe permite exercer a sua criatividade de forma completamente autônoma.

Segundo Grotowski, nas performances de tradição oriental que estão na linhagem artificial do teatro, o como fazer ou a forma é mais importante que o envolvimento emocional do ator em ação. Dito isto, Grotowski utiliza a expressão tendência artificial no sentido positivo do termo, se referindo à predominância da estrutura, da forma, da composição e da montagem para a criação de uma obra.

O trabalho de Bertold Brecht no Ocidente seria, segundo Grotowski, o que mais se aproxima da abordagem artificial. Na verdade, com

1 Étienne Decroux (1898-1991), ator, diretor, pedagogo francês, aluno de Jacques Copeau, dedicou quase 60 anos de sua vida a uma pesquisa para que "o ator seja o músico instrumentista de seu próprio corpo", ou seja, que o ator possa ser simultaneamente "músico" e "instrumento" e que, como músico, aprenda impecavelmente a técnica de tocar seu instrumento para poder dar sua interpretação pessoal no momento de "tocar uma partição". Decroux criou então um sistema de técnicas corporais categorizadas com o objetivo de pesquisa e transmissão para que o ator venha a ser um ator criador e não apenas seguir as indicações do encenador e do autor do texto. 
Brecht, os atores trabalhavam seus movimentos rigorosamente para encontrar uma maneira específica para transmitir suas ideias. Nesta perspectiva, é interessante notar que a palavra artificial é etimologicamente relacionada com a palavra arte. Assim, a artificialidade deve ser entendida como um recurso que permite dar forma a uma emoção, a uma ideia, afim de torná-la o mais universal possível para chegar ao espectador. A montagem, por exemplo, que é uma ferramenta formal, presente tanto no teatro como no cinema, e tem como objetivo criar um percurso para conduzir a atenção do espectador.

Se no teatro tradicional asiático o corpo do ator sempre ocupou um lugar fundamental, no Ocidente, sobretudo na Rússia e Europa, apesar do grande trabalho desenvolvido por François Delsarte ${ }^{2}$, foi só no inicio do século XX que começaram as pesquisas, intervenções e técnicas corporais dos chamados Grandes Reformadores do teatro, entre eles Stanislavski, Meyerhold, Gordon Craig, Appia, Jacques Copeau, Antonin Artaud, Jerzy Grotowski e Étienne Decroux. Nascia então um grande interesse dos profissionais de teatro e dos atores por técnicas corporais. Efetivamente, um dos avanços mais importantes destes reformadores baseia-se no anseio de colocar o ator no centro do teatro como um artista criador, e isso exige, necessariamente, um domínio do próprio corpo e da voz por parte do ator. $\mathrm{O}$ envolvimento do ator tornou-se maior, a ponto de permitir-lhe uma autonomia com relação ao dramaturgo.

Étienne Decroux, mergulhou numa pesquisa

\footnotetext{
2 François Delsarte (1811-1871), cantor, orador e pedagogo francês que deixou um vasto material de pesquisa para que o artista pudesse ter acesso a uma harmonia entre os três elementos humanos importantes: o corpo, a emoção e o intelecto.
}

por quase 60 anos, para encontrar as possibilidades corporais do ator. Criou um sistema de trabalho que chamou de Mimo Corpóreo e considerava-o como um "Grande Projeto" (Leabhart apud Pezin, 2003, p. 467), o qual ele idealizou metaforicamente como a construção de uma catedral, para a qual seriam necessárias várias gerações de artesãos e que a construção não permitiria, em última análise, identificar um único autor da obra. Decroux não queria fazer parte da tradição do teatro ocidental, contribuindo com novas técnicas. Na verdade, ele queria criar um novo gênero de arte, uma forma teatral autônoma. De acordo com Eugenio Barba, "Étienne Decroux é talvez o único mestre Europeu que elaborou um conjunto de regras semelhantes às de uma tradição asiática" (Barba: Savarese, 2008, p.14) e nesse processo, Decroux provavelmente percebeu a tarefa que ele mesmo se comprometeu à realizar. Mas, embora tendo a vontade consciente de desenvolver um sistema complexo, Decroux começou sua pesquisa a partir da necessidade, um senso de urgência,de uma técnica e mesmo de uma ética para ator de seu tempo.

$\mathrm{Na}$ verdade, nesse período os atores não tinham um sistema de trabalho corporal que fosse específico, pois até então, apenas o ballet tinha desenvolvido um sistema minucioso. Claro, já existia o sistema Delsarte na Europa, mas tinha sido em grande parte esquecido; havia também a Rítmica de Dalcroze em Genebra a qual Jacques Copeau se interessou durante um período, mas era direcionada sobretudo aos músicos. Houve também o Sistema de Notação Laban, mas também dirigido a um público específico, os bailarinos; e na Rússia, iniciava a biomecânica de Meyerhold. Porém, no teatro francês, não havia um sistema educacional, nenhum método de trabalho, 
que permitisse ao ator ganhar domínio técnico corporal.

No teatro tradicional asiático, os atores começam a formação muito jovens, com um treinamento corporal muito forte, que os leva a colocar seus corpos a serviço da arte. Este treinamento corporal inclui exercícios de flexibilidade, de resistência, de postura, alinhamento da coluna vertebral, ou exercícios direcionados às articulações, os quais correspondem especificamente para a forma tradicional que eles terão que dominar e interpretar mais tarde. Em paralelo, eles aprendem os gestos, as canções, as histórias e todos os elementos que compõem esse universo. O Mimo Corpóreo de Étienne Decroux parece se encaixar na linhagem artificial, além de outras características, tanto pela exigência de um longo período de treinamento técnico junto a um mestre ou professor, como pela ausência de engajamento emocional que o ator deve manter em relação à ação.

O Mimo Corpóreo deve ser aprendido e praticado por pelo menos três anos antes que o ator/mímico possa realmente dominar a técnica, afim de tê-la como uma ferramenta de criação artística. Quem transmite esta técnica também deve passar por um longo período de treinamento. $\mathrm{Na}$ verdade, Decroux falava de uma exigência de tempo mínimo para o estudo do Mimo Corpóreo: "Para que a mímica exista, é necessário que haja escolas de mímica. Que nelas tenham alunos que possam permanecer por cinco ou seis anos e que eles estudem como se estuda a música" (Decroux apud Pezin, 2013, p. 92).

O aprendizado e a prática do Mimo Corpóreo são marcados pelo rigor, pela precisão e a necessidade de seguir um professor, bem como as múltiplas e complexas categoriza- ções construídas para esse aprendizado e a transmissão dessa técnica. Dadas estas características, surge uma pergunta: é possível que o trabalho desenvolvido por Decroux seja classificado como parte da linhagem artificial, tal como definida por Grotowski, à qual ele inclui as formas de teatro tradicional asiático?

Em realidade, Decroux não teve nenhuma experiência notável para ser realmente influenciado pelo teatro oriental e, pelo fato de não ter seguido nenhuma dessas formas como pesquisa, pode-se dizer que seu sistema é original. Mas, é possível observar diversos elementos de algumas formas teatrais do Oriente, que o inspiraram, dentre as quais o teatro Nô seja, talvez, a que o estimulou em particular.

Kathryn Wylie que foi uma estudante de Étienne Decroux identifica várias semelhanças entre sua experiência como aluna de Decroux e a prática de teatro Nô: "disciplina estrita baseada na imitação de um mestre, iniciada em uma idade jovem e continuada ao longo de toda vida; um método que exige auto sacrifício na aquisição da técnica, o estudante não deve simplesmente imitar a forma exterior, mas deve penetrar na essência de uma figura ou de um movimento para descobrir as impulsões de onde os 'movimentos fluem'; resfriamento da emoção que é traduzida pela técnica, afim de criar uma expressão impessoal de uma emoção ou uma ideia universal; modelos de movimentos abstratos e simbólicos extraídos de uma estética de movimento baseada em princípios da escultura e da arquitetura; uma preferência pela atitude mais do que pelo gesto em si; uma técnica que se resume ao equilíbrio precário entre as forças de resistência e o tempo da ação; a importância da economia de movimentos; a ideia de imobilidade transportada" (Wylie, 1993-1994, p. 111-112). 
Voltando a Grotowski, ele nos dá outros pontos que diferenciam a abordagem artificial da abordagem orgânica, tais como: a busca da expressividade; a transmissão de pai para filho; a predominância de posições e sinais; a ausência de engajamento emocional.

Neste artigo, tentarei localizar o Mimo Corpóreo de Decroux no item a busca da expressividade.

Podemos dizer que a busca da expressividade é uma prática ou um objetivo das artes cênicas contemporâneas num sentido amplo. A expressividade no campo teatral é entendida como um conjunto de meios, entre outros, físicos: corpo, voz, material (objetos, luzes, maquiagem, figurinos, instrumentos, etc.), literatura (textos teatrais, poesia, etc.) para transmitir uma ideia, uma visão do mundo, com diferentes objetivos segundo as culturas e épocas: criticar, estimular, emocionar, educar, deleitar, etc. Assim, a busca de expressividade é um trabalho de selecionar os meios e preparação para atingir estes objetivos específicos. Para Grotowski a busca da expressividade é também uma das características da linhagem artificial, embora possa parecer paradoxal.

Agora, para entender a afirmação de Grotowski, deve-se notar que ele faz uma distinção entre a pesquisa da expressividade do ator contemporâneo que "torna-se criativo, porque alguém o assiste" e a pesquisa daquele que é "criativo e depois alguém vai assisti-lo." Assim, o primeiro ator é aquele que trabalha no que Grotowski chama de Artes do Espetáculo ou Artes Espetaculares, e se caracteriza por uma espécie de aspiração de se expressar, mas que muitas vezes é um desejo decorrente de necessidades pessoais superficiais tais como a vaidade, o anseio de ser aceito ou ainda de provocar o público. Por isso, procura so- bretudo uma expressão em seu trabalho, que, aliás, é uma reivindicação artística legítima. No entanto, observa Grotowski, o que este ator faz não é necessariamente arte em si, embora este ato pode se tornar arte aos olhos de alguém que o observa. É, em última análise, "o olhar do outro, pode-se dizer do espectador, que é a fonte do termo Artes Espetaculares" (Grotowski, 1997).

O segundo ator é aquele que Grotowski vincula ao termo inglês Performing Arts, onde o foco é sobre o próprio ator, ou como disse Grotowski "aquele que faz", como sugerido pelo verbo contido na expressão anglo-saxônica. Nesse termo, ele aspira reunir tanto o teatro como o ritual. Acima de tudo, ele quer que o termo espelhe essa característica dos atores que não estão procurando a expressividade num primeiro momento, mas, passando por um longo período de aprendizagem e pesquisa, Ihes permitirá ganhar experiência semeIhante a uma batalha consigo mesmo, e após a qual eles possam talvez ser compreendidos por alguém que os assista. Grotowski afirma que há uma grande diferença entre os conteúdos da abordagem do teatro e do ritual nas Artes do Espetáculo e no Performing Arts.

Na primeira fase da linhagem orgânica grotowskiana o ator não busca antes de tudo a expressividade, porque durante o processo, ele se dirige a si mesmo para obter o que Grotowski chama de "lucidez, transparência". $\mathrm{Na}$ fase seguinte, a da criação da estrutura, da montagem que será apresentada ao público, haverá uma espécie de busca de expressividade, mas será, em realidade, um arranjo de todos os materiais criados pela experiência do ator. Este material vai ser, naturalmente, organizado em uma estrutura pessoal de cada ator. Será então o trabalho do diretor que nesta fase 
será voltado para o público.

$\mathrm{Na}$ linhagem artificial, a questão da expressividade é singular. Nas formas tradicionais de teatro tradicional asiático, sejam elas rituais sagrados ou que tenham sido convertidas em formas teatrais a partir de manifestações populares ou a partir da literatura, houve originalmente investigações profundas da expressividade. Elas foram criadas para transmitir histórias através de formas altamente codificadas e, portanto, artificiais. Os gestos dos personagens seguiram regras estritas de criação, como a individualização na ópera chinesa que desenvolve uma maneira de colocar em evidencia os traços principais do personagem em uma forma não-realista. As criações da Ópera de Pequim são inspiradas a partir de peças clássicas, de literatura popular (histórias fantásticas ou mitológicas ou de biografias, lendas e de acontecimentos históricos chineses.

Ao longo dos anos, ou mesmo séculos, as formas tradicionais não mudaram e os atores destas formas não devem apresentar criatividade ou inventividade no sentido de uma pesquisa da expressão pessoal. Em vez disso, eles devem seguir o que os seus mestres lhes transmitiram e aprenderem a atuar nas peças exatamente como elas foram criadas e reproduzidas por gerações. Neste caso, embora a forma teatral seja muito expressiva, o ator que interpreta esta forma não procura transmitir a sua manifestação individual, ele meramente se contenta em servir como instrumento de transmissão. O ator oriental é, então, o oposto desse tipo de ator que Grotowski menciona na categoria de Artes Espetaculares, no que concerne a busca de uma expressão pessoal. Entretanto, o ator destas formas tradicionais está plenamente consciente do seu papel e da sua relação com o público a quem ele transmite o significado de sua arte. Ele é expressivo, mas não no sentido que pode ser percebido um ator ocidental, porque não se limita a repetir o que ele aprendeu de cor durante seu aprendizado. De fato, em sua formação, além do aprendizado de uma forma artística, ele também desenvolve sua qualidade de Presença cênica e suas habilidades de interação, que contribuem para aumentar e cultivar suas capacidades de expressão. Isto significa que sua relação com o público permanecerá viva constantemente.

Várias formas de teatro oriental muito refinadas cativam a atenção do espectador, e o ator é consciente desta característica. George Banu mostra que, ao contrário do ator Ocidental, "o ator Oriental assume sempre a presença dos espectadores. Ele atua para eles, adota a direção direta ou se expõe tal como um objeto de arte para que olhos expertos o admirem, na maioria das vezes, por razões de plasticidade. Instalado frontalmente na sala, ele estabeleceque este espaço é, decisivamente, seu colaborador". (Banu, 2005, p.18-21).

Existem formas tradicionais como por exemplo o Kutiyattam do Kerala, no sul da Índia, os atores atuam "vilakkinu nere", ou seja, dirigidos para a lâmpada, um tipo de pedestal de metal dourado cuja chama é alimentada por óleo e permanece acesa durante todo o espetáculo. No entanto, o ator é muito consciente de que ele tem que transportar o público a uma experiência estética através dos mudra-s, que foram minuciosamente estudados e analisados pelos antigos esteticistas indianos (Venu, 2013, p. 5-6).

Se a busca de expressividade no Oriente permite que o ator esteja intimamente ligado ao público para poder transmitir-lhe uma história expressa por códigos e mantê-lo cativado do começo ao fim, isto se dá devido aos ob- 
jetivos das tradições e não a uma escolha do próprio ator. No Ocidente, há um tipo diferente de pesquisa de expressividade altamente desenvolvida, por exemplo, a de Marcel Marceau, que, de acordo com Grotowski, criou um trabalho muito rico voltado para o público e que tem um valor artístico real. Mas Grotowski expressa claramente, antes que Decroux, antes de Marceau, havia começado este trabalho corporal, mas sem tentar ser expressivo, pelo contrário, ele procurou "as leis da vida que fluem" (Grotowski, 1997).

Para os atores ocidentais, este mesmo propósito de expressividade dirigida para o espectador tem um problema real, porque, na maioria das vezes, eles não se envolvem em um trabalho de pesquisa profunda. É por isso que muitas vezes eles recorrem a uma acumulação de artifícios e truques para dissimular a falta resultante desta deficiência. Grotowski explica: "Esse "arsenal" ou estoque pode não ser mais que uma coleção de clichês, caso em que tal método é inseparável do conceito do "ator cortesão". A expressão cortesão é usada por Grotowski como o oposto do ator santo. O primeiro seria aquele que é "explorado por dinheiro ou para ganhar a simpatia do público", enquanto o ator santo revela-se "tirando sua máscara do cotidiano" (Grotowski, 1992, p. 29-30), e isso só pode acontecer depois de um longo processo de trabalho.

Decroux, bem como Grotowski está entre aqueles que mergulham na pesquisa. Só depois de um estágio avançado de trabalho que eles estão dispostos a compartilhar suas criações. Na verdade, em sessenta anos de pesquisa no Mimo Corpóreo, Decroux consolidou seu sistema técnico que permite que uma manifestação metafísica venha para a superfície. Ele estudou cuidadosamente as relações entre as partes do corpo, entre corpo e espaço e entre dois ou mais corpos. Procurou as infinitas possibilidades das articulações, as qualidades dinâmicas do movimento ou mesmo o não-movimento, ou ainda a intensidade dramática adquirida pelo estudo do peso e do contrapeso do corpo do ator.

Se na origem da Ópera de Pequim, há uma pesquisa corporal para encontrar a individualização, isto é, uma gestualidade muito precisa que permite ao público reconhecer imediatamente um personagem; no Mimo Corpóreo, Decroux primeiro explorou para depois compor as gestualidades características de certos tipos humanos. Mas para ele, o objetivo era criar estas figuras para serem usadas como estudos, como muitas vezes é feito na música. Ele chamou essa pesquisa de categorias de atuação do Mimo Corpóreo.

Decroux partiu da observação do homem/ mulher em suas atividades ou nos seus ambientes habituais, tais como trabalho, esportes, passatempos, sonhos. Ele explorou os movimentos humanos, do mais primitivo, do mais simples ao mais sofisticado. Esta pesquisa se baseou na observação e, é claro, na prática que ele trabalhava com seu próprio corpo.

Do seu trabalho resultaram, além de várias peças, as figuras de estilo, ou categorias de atuação, criadas para fins pedagógicos. Essas categorias têm valor para a transmissão, uma vez que facilitam a compreensão corpórea a partir da visualização dos tipos. Naturalmente, as peças criadas para cada uma destas categorias não são clichês. Estilizadas, elas seguem os princípios próprios para a categoria a que dizem respeito.

O poder analítico de Decroux permitiu construir um sistema de compreensão e de transmissão de sua arte; também lhe permitiu 
vislumbrar e declarar que, mesmo sem gostardas palavras científicas, seu estudo pode ser descrito como "histórico-econômico", dada a relação com a vida, a sobrevivência e a evolução humana. Graças ao Mimo Corpóreo, a demonstração da relação que o homem mantém com o peso, de acordo com sua ocupação ou seu lugar na sociedade, não é apenas um bom eixo para determinar as categorias do Mimo Corpóreo, mas serve também para fazer um retrato da sociedade. Para ele, as seguintes categorias têm diferentes relações com o peso e contrapeso do corpo:

- O Homem do Esporte, com três subcategorias: O Homem do Esforço; O Artesão, O Homem das Ilhas;

- O Homem do Salão;

- O Homem do Sonho;

- A Estatuária Móvel.

\section{O Homem do Esporte}

Tomando a perspectiva do estudo "histórico-econômico", a categoria O Homem do Esporte inclui atividades humanas relacionadas à produção, ao trabalho, e que estão gerando desenvolvimento econômico. Esta categoria compreende os trabalhos físicos, dos mais rudes tais como os relacionados com a agricultura, a construção e aqueles relativamente menos penosos, como aqueles das lavadeiras $^{3}$, das costureiras, etc. Todos são parte do sistema produtivo. O termo O Homem do Esporte dado por Decroux significa que a figura do esporte simboliza o trabalho físico humano. Conforme a evolução tecnológica, o trabalho

3 Lembrando que Decroux criou essas categorias nos anos trinta, onde os eletrodomésticos eram limitados, portanto não havia máquinas de lavar roupas. do homem é substituído pela máquina, o esporte representa então a memória do homem trabalhador. Esta categoria representa o trabaIho físico do homem que, fundamentalmente, o peso é explorado numa escala que vai do mais leve ao mais pesado.

Os movimentos que fazem parte desta categoria envolvem uma gama de pesos e, em consequência, de contrapesos, tais como empurrar, puxar, levantar, lançar, etc. O esforço muscular exigido no trabalho e no esporte é transferido na atuação com peso e determina a qualidade dramática do movimento. Quanto maior o esforço, mais dramático será o movimento.

Todos os movimentos feitos a partir do real, uma tarefa humana, um trabalho físico ou um esporte, dão uma qualidade especial ao movimento. Mas, surpreendentemente, eles têm a mesma força quando nascem do pensamento. Neste caso, o peso físico da ação, a sua dificuldade material é substituída pelo peso metafísico que representa o pensamento, isso significa que a resistência muscular que se manifesta no movimento vem de um movimento da mente: as dúvidas, as hesitações, as ideias se corporificam e esculpem o movimento do ator.

$\mathrm{Na}$ subcategoria O Homem do Esforço, o "faz tudo", como diz Decroux (1963, p. 113), o peso é a principal característica, o que ele empurra, levanta ou puxa é geralmente muito pesado. Para tornar visível o peso dessa carga, o movimento irá incluir muitas imobilidades. As composições incluem as imobilidades transportadas, entre as quais o grand composé, que se caracteriza por um deslocamento sem alterar o desenho do corpo, refletindo o esforço feito pelo corpo. Haverá também paradas de qualidades variáveis e vibrações mais ou menos fortes. 
As figuras presentes nessa subcategoria servem particularmente como estudo prático da escala de resistências corporais. Elas ajudam também a trabalhar o jogo de tensão e relaxamento, e, especialmente, para dar a oportunidade de explorar todos os níveis na escala de tensão/relaxamento, ou seja, para conseguir resistências mais fortes e, de maneira correlativa, uma grande expansão do corpo em movimento e, por conseguinte, a Presença cênica.

Outro ponto importante nesta categoria é o de contato que o ator estabelece com o solo, porque no caso de movimentos fortes para levantar, empurrar, uma espécie de enraizamento dos pés do ator no solo é necessária. Em paralelo, e para que a imagem do homem num trabalho de esforço se torne visível, um trabaIho de imaginação e controle do espaço por parte do ator será muito importante.

$\mathrm{Na}$ subcategoria O Artesão, encontram-se os trabalhos que incluem gestos para bater, lavar, lixar, e que envolvem movimentos específicos. As qualidades de movimento estão relacionadas com os tipos de tarefas executadas, mas também com as qualidades de pensamento que são implantados no momento da realização, ou seja, o pensamento naquele momento, sobre o trabalho feito, mas também o pensamento em geral que se reflete no movimento. A qualidade do movimento é então caracterizada pelo jogo das ações e das paradas: as diversas resistências musculares são adequadas ao peso necessário na ação do momento, e se alternam com o movimento do pensamento. Na subcategoria $\mathrm{O}$ Homem das Ilhas, Decroux criou movimentos caracterizados pela harmonia e um fluxo constante, mas as qualidades dinâmicas têm diferenças sutis entre elas.
Decroux deu o nome de O Homem das Ilhas a uma série de movimentos por imaginar um lugar onde os homens realizam trabalho físico, mas sem grande força muscular, e onde, embora possa haver resistência, esta é compensada pelo fato de que há óleo nas articulações do corpo. As articulações corporais realizam então trabalhos mais minuciosos. O importante é não só executar a tarefa, mas estar ciente da qualidade da fluidez das partes do corpo mobilizadas pelo movimento, e até mesmo a sensação de prazer que pode trazer a realização dessas atividades. $O$ ator deve ter um contato muito próximo, não com suas emoções ou seus pensamentos, mas com todo o seu corpo, tentando sentir a sua massa corporal, os fluidos internos que se espalham com os movimentos e as sensações que surgem quando o ator está ciente de todo o seu ser.

\section{O Homem do Salão}

Como indicado pela expressão, O Homem do Salão é uma categoria que representa o homem em seu ambiente social. Aqui predomina a polidez, o que cria um gesto refinado e delicado. Decroux disse que essas atitudes nascem da hipocrisia humana. Eles refletem o desejo do homem que quer mostrar a imagem de um ser social, mas com comportamentos que não correspondem à realidade. Decroux (2001, p. 99) explica:

\footnotetext{
É assim que o homem sabendo que nem sempre é bom, adoraria sê-lo o tempo todo. O que ele faz? Ele finge, atua a qualidade da bondade. Ele não engana ninguém, mas isso lhe dá prazer! É como um exercício para o coração, uma esperança de que, atuando a bondade, nós vamos finalmente tê-la. E isso é algo muito bonito.
} 
Ainda com relação ao estudo histórico-econômico, nessa categoria o homem não produz nada "que possa ser vendido". E, neste estudo, os movimentos são leves, sejam lentos ou rápidos, eles não mostram resistência muscular muito acentuada. Muitos movimentos são amplos. As ações cotidianas como sentar, beber, dar, receber são realizadas com grande delicadeza e parecem dilatadas. Estas ações são geralmente realizadas em linhas curvas, de acordo com Decroux para não "machucar o espaço".

\section{O Homem do Sonho}

Os movimentos do grupo O Homem do Sonho são caracterizadas por ações sem acentos pronunciados, por um ritmo lento e sem esforço ou resistência muscular. Estas ações são feitas em um estado de equilíbrio precário, isto é, o centro de gravidade do corpo é mudado do centro, onde está a segurança, para um outro lugar onde a queda é provável. $O$ ator cultiva assim um estado de desequilíbrio constante.

Os planos inclinados, que causam instabilidade corporal, são amplamente utilizados para, assim, dar a imagem e a ideia do homem que lembra de sua vida, ou que sonha, mesmo acordado. Os movimentos do corposeguem então a memória, o sonho.

\section{Estatuária Móvel}

A Estatuária Móvel é, talvez, a categoria mais abstrata do Mimo Corpóreo. Caracteriza-se por movimentos sinuosos e pela decomposição e recomposição das diferentes partes do corpo. Inclui a ideia de que "todo o sistema muscular reflete o pensamento" (Decroux, 2001, p. 101). Não há representação da realidade, os movimentos corporais seguem o movimento do pensamento, os movimentos são a corporificação do pensamento, são o próprio pensamento.

Os movimentos serão caracterizados por alterações de ritmo e de dinâmica. Na verdade, a mente humana tem suas surpresas, suas paradas, suas mudanças de direção, podendo chegar à oposição, mesmo dentro do que estava sendo desenvolvido na mesma.

Decroux não buscava maneiras de ser expressivo, ele pesquisava as manifestações do comportamento humano em ambientes diferentes e, especialmente, em diferentes atividades. Ele procurou primeiro entender a mecânica e a energia que anima o homem. Mas seu estudo profundo do funcionamento do corpo não se limitou a alcançar uma melhor performance teatral ou cênica. Suas pesquisas e sua criação das categorias do Mimo Corpóreo também são pesquisas que tiveram como objetivo compreender o homem.

Étienne Decroux colocou em evidencia uma gramática, um vocabulário corporal específico que ele criou para fins pedagógicos e não performativos. Essa semiótica, todas essas categorizações de gestos, atitudes, forças de oposições, entre outros, estão longe de classificações fixas, porque a energia interior, o fluxo vivo, sempre foi aquilo que esteve originalmente nos movimentos deste mestre.

A pesquisa de uma técnica, a estilização de movimentos, de figuras de estilos, em suma, de uma artificialidade permite liberar o poder poético do corpo e enriquecer o espaço cênico de uma linguagem própria. Se isso foi levado ao extremo por Decroux, pesquisadores de 
linguagens teatrais contemporâneas, mesmo aquelas chamadas de orgânicas, também poRecebido: 19/04/2017 dem recorrer a este trabalho de estilização.

\section{Referências}

Alaniz, Sirlei (Leela), Le Corps qui pense, l'esprit qui danse, l'acteur dans as quête de I'unité perdue, Thèse de Doctorat, Paris, Université Sorbonne Nouvelle, Paris III, 2014.

Banu, Georges, “L'acteur oriental”, in L'art du comédien, Documents pour la Classe, n`897, Paris, Centre national de documentation pédagogique, 1er juin 2005.

Barba, Eugenio et Savarese, Nicola, L'Énergie qui danse, dictionnaire d'Anthropologie Théâtrale, Montpelier, L'Entretemps, 2008.

Decroux, Étienne, "Categories of Corporeal Mime", in An Étienne Decroux Album, Mime Journal, Claremont (Californie), Pomona College, 2001.

Decroux, Etienne, Paroles sur le mime, Paris, Librairie Théâtrale, 1963.

Grotowski, Jerzy, Em busca de um teatro pobre, Rio de Janeiro, Ed. Civilização Brasileira, 1992.

Grotowski, Jerzy, "Leçon inaugurale au Théâtre des Bouffes du Nord", in Anthropologie théâtrale, Cassette, face A, Collection Collège de France, Paris, Le Livre Qui parle, le 24 mars 1997.

Pezin, Patrick Éd., Étienne Decroux, mime corporel, Paris, L'Entretemps, 2003.

Wylie, Kathryn, "Apologia for Decroux", in Words on Decroux - Mime Journal, Claremont, Californie, Pomona College éd., 19931994.Recebido: 15/05/2017 